\title{
早三叠世海水的碳同位素组成与演化 来自四川盆地东部的研究
}

\author{
黄思静"，黄可可，吕杰，兰叶芳 \\ 油气藏地质及开发工程国家重点实验室(成都理工大学), 成都 610059 \\ *E-mail: hsj@cdut.edu.cn \\ 收稿日期: 2011-11-23; 接受日期: 2012-04-18 \\ 国家自然科学基金(批准号: 40839908, 41172099)资助
}

\begin{abstract}
摘要作为地球历史中最严重生物灭绝事件之后的生态萧条时间间隔的早三叠世海水 的碳同位素组成与演化为人们所高度关注, 但研究仍处于较低水平. 本文测试了四川盆地 东部二叠纪末至早三叠世 113 个海相碳酸盐样品的碳、氧同位素组成, 建立了相应的碳同 位素演化曲线, 同时分析了样品的 $\mathrm{CaO}, \mathrm{MgO}, \mathrm{Mn}$ 和 $\mathrm{Sr}$ 含量, 并对少数受热化学硫酸盐还 原作用影响的碳同位素组成样品进行了校正, 以使样品的碳同位素组成对海水都具有较好 的代表性. 研究表明, 四川盆地东部早三叠世海相碳酸盐的 $\delta^{13} \mathrm{C}$ 值具显生宙最大的波动范 围, 在约 $5 \mathrm{Ma}$ 的时间中 $\delta^{13} \mathrm{C}$ 值从约 $-2 \%$ 的最小值变化到 $8 \% 0$ 的最大值, 变化幅度达 $10 \%$, 这与前人在贵州建立的同期碳酸盐碳同位素演化曲线类似，但与下扬子安徽巢湖地区同时 代演化曲线存在显著的差别 $\left(\delta^{13} \mathrm{C}\right.$ 值从约 $-6 \%$ 的最小值变化到 $4 \%$ ). 早三叠世全球范围大 陆植被的减少、海洋钙质无脊椎动物和海相碳酸盐数量的减少, 以及海洋系统中菌、藻类 的过度繁盛、产甲烷菌活跃可能是早三叠世海水极高的 $\delta^{13} \mathrm{C}$ 值和同位素组成大幅度波动的 重要原因, 甲烷的形成可能在局部地方大幅度提高了海水的 $\delta^{13} \mathrm{C}$ 值(并可能导致了白云石 的沉淀); 这可能也是早三叠世碳同位素组成具有一定地方性色彩的原因, 这种现象在早-中 三叠世界线附近结束, 海水 $\delta^{13} \mathrm{C}$ 值得以稳定, 表明地球系统生态环境得以重建和恢复. 作 为碳同位素调节器的大陆植被和海洋钙质无脊椎动物在地球生态系统中具有不可替代的 作用, 我们不但要保护热带雨林, 也要像保护热带雨林那样保护海洋钙质无脊椎动物.
\end{abstract}

\section{关键词}

四川盆地东部

早三叠世

海水碳同位素组成 碳同位素调节器 生态破坏与重建
二叠纪末期发生了自地球上有生命以来最严重 的生物灭绝事件, 到约 $251 \mathrm{Ma}$ 的二叠纪-三叠纪界线 处, 全球可能有 $90 \%$ 左右的海洋物种消失 ${ }^{[1,2]}$. 其后 的早三叠世是一个生物逐渐复苏的时期, 但早三叠 世仍然缺失很多在二叠纪和中三叠世存在的海洋生 物, 同时早三叠世海洋无脊椎动物体型较小, 陆地缺
乏煤的沉积, 这些都说明早三叠世是一个全球生态 萧条的时间间隔，持续时间约 $5 \mathrm{Ma}$ (到中三叠早期), 这意味着海洋生物多样性及生态系统的重建大致用 了 $5 \mathrm{Ma}$ 的时间. 地球历史上很多生物灭绝与复苏事 件都伴随着海相碳酸盐碳同位素组成的变化, 对这 种变化的研究有助于我们理解生物灭绝与复苏的机

英文引用格式: Huang S J, Huang K K, Lü J, et al. Carbon isotopic composition of Early Triassic marine carbonates, Eastern Sichuan Basin, China. Sci China Earth Sci, 2012, doi: 10.1007/s11430-012-4440-1 
制. 同样, 与早三叠世生态萧条及重建过程有关的全 球碳循环信息也记录在了相应的海相碳酸盐的碳同 位素中, 因而人们对早三叠世全球海相碳酸盐的碳 同位素组成十分关注. 然而遗撼的是: 早三叠世是显 生宙海水碳同位素组成研究最薄弱的时间间隔. Veizer 等 ${ }^{[3]}$ 所建立的显生宙海水碳同位素曲线中, 早 三叠世时间段缺乏足够的分辨率, 这与地球上很多 地方早三叠世都以巨厚的碎屑沉积为主 ${ }^{[4]}$ 、古海水信 息的获取相对困难有关.

已公布的不同地区早三叠世海相碳酸盐的碳同 位素组成与变化幅度存在显著差别, 但其原因并不 清楚. 在全球范围早三叠世海相碳酸盐的碳同位素 研究中, 首先要提及的是我国地层学工作者对下扬 子地区早三叠世海相碳酸盐碳同位素组成的系统研 究, 涉及的剖面包括安徽巢湖和浙江煤山等多个地 区, 各剖面都有良好的生物地层学基础工作, 分析的 数据可能已超过 1000 个, 如 Tong 等 ${ }^{[5]}$ (图 1) 和 Zuo 等 ${ }^{[6]}$ 卓有成效的工作. 然而已报道的世界其他地方较 为系统的早三叠世碳酸盐碳同位素组成研究成果屈 指可数, 包括: (1) Korte 等 ${ }^{[7]}$ 对欧洲和西亚(包括意大 利、匈牙利、斯洛伐克、德国和伊朗) 海相碳酸盐的 碳同位素研究 (图 2, 图中同时涉及了文献 $[8,9]$ 的数 据), 但早三叠世的数据明显不完整, 缺乏整个 Spathia 亚阶和部分 Smithian 亚阶的样品; (2) Horacek 等 ${ }^{[12]}$ 对位于意大利北部海相碳酸盐碳同位素的研究, 其所建立的早三叠世海水的碳同位素演化曲线基本 上是完整的(图 3). 除此之外, Payne 等 ${ }^{[13]}$ 报道了对中 国贵州三个早三叠世地层剖面的高分辨率碳同位素 研究, 在这三个剖面中, 只有关刀剖面(图 4) 的早三 叠世数据是完整的. 我们将这些早三叠世海相碳酸 盐的研究成果作如下总结:
(1) 早三叠世碳同位素组成研究中所使用的都 是全岩样品, 说明全球范围内用以进行早三叠世古 海洋学研究良好样品(如腕足类生物壳) 获取的困难 性. 虽然 Korte 等 ${ }^{[7]}$ 综合的阿尔卑斯和伊朗的数据中 有一些腕足样品, 但这些样品都没有分布在早三叠 世(图 2(b)); 在 Payne 等 ${ }^{[13]}$ 对中国贵州和 Horacek 等 ${ }^{[12]}$ 对意大利北部的研究中, 很多用于碳同位素研究的 样品都是白云岩, 但作者认为这些白云岩的碳同位 素组成并没有偏离海水, 只有氧同位素组成偏离了 海水，因为样品的碳、氧同位素之间没有相关性.

(2) 各剖面早三叠世海水的 $\delta^{13} \mathrm{C}$ 值具有非常大 的波动范围, 但变化细节上存在显著差别, 贵州关刀 剖面的 $\delta^{13} \mathrm{C}$ 的最大值达到了 $6 \%$, 出现在 Dienerian 亚阶和 Smithian 亚阶之间(图 4), 该地区报道的另外 两个剖面的 $\delta^{13} \mathrm{C}$ 的最大值达到了 $8 \%$; 在意大利北部 的两个下三叠统剖面中, Uomo 剖面的 $\delta^{13} \mathrm{C}$ 最大值接 近 6\%o, 也出现在 Dienerian 亚阶和 Smithian 亚阶之间 (图 3); 在 Korte 等 ${ }^{[7]}$ 综合的阿尔卑斯和伊朗的数据 中, $\delta^{13} \mathrm{C}$ 最大值不到 $4.5 \%$, 没有出现在 Dienerian 亚 阶和 Smithian 亚阶之间, 而出现在了早、中三叠世界 线附近(图 2), 这种情况也与安徽巢湖平顶山北坡剖 面 Spathian 亚阶的 $\delta^{13} \mathrm{C}$ 高值的情况(图 1)类似.

（3）下扬子地区多数剖面早三叠世碳酸盐的 $\delta^{13} \mathrm{C}$ 值普遍较低, 如平顶山北坡剖面 Griesbachain 亚 阶的样品全部小于 0 , 在其他地区早三叠世的样品 中, 除靠近二叠纪-三叠纪界线附近的样品外, 大多 数 Griesbachain 亚阶的样品的 $\delta^{13} \mathrm{C}$ 值都是正值, 尤其 是贵州关刀剖面(包括 Payne 等 ${ }^{[13]}$ 报道的贵州其他剖 面)早三叠世的样品中, 除 Smithian 亚阶以外, 其余 样品大都为正值.

上面的讨论说明, 虽然早三叠世作为显生宙最

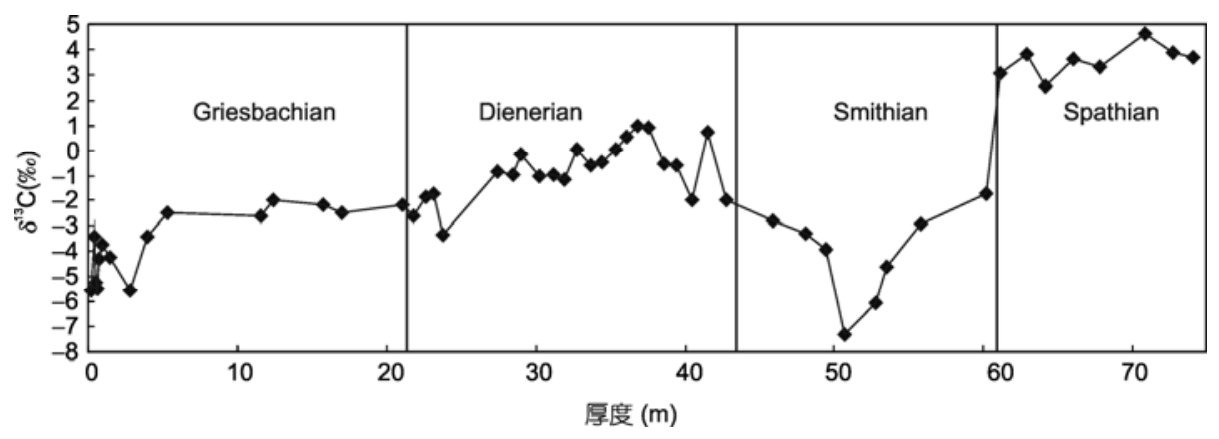

图 1 安徽巢湖平顶山北坡剖面碳酸盐的碳同位素演化曲线

据 Tong 等 ${ }^{[5]}$ 的数据重绘 

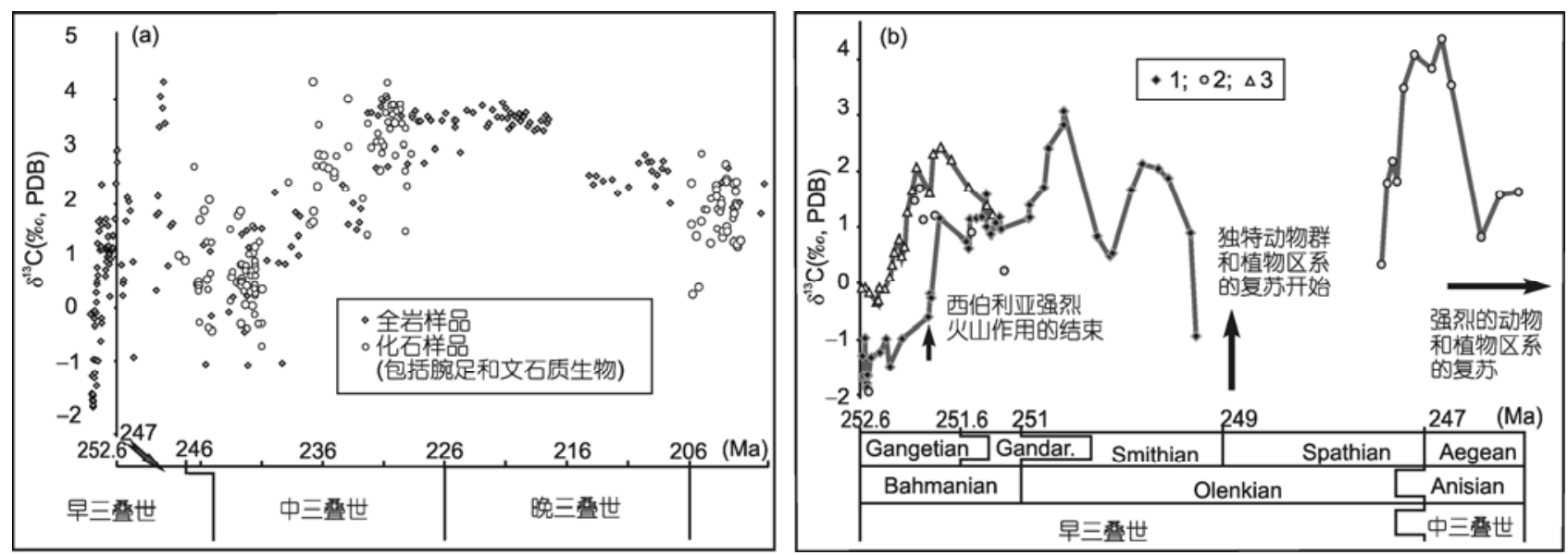

图 2 三叠纪海水的碳同位素组成及演化趋势(a)及早三叠世部分的局部放大(b)

(a) 据文献[7 9]; (b) 三叠纪年龄刻度按文献[10, 11]. 1. 全岩样品(Pufels, Southern Alps, 据文献[7, 9]); 2. 全岩样品(Palazzo Adriano, Sicily, 据文献[7]); 3. 全岩样品(Abadeh, Iran, 据文献[8]的数据)

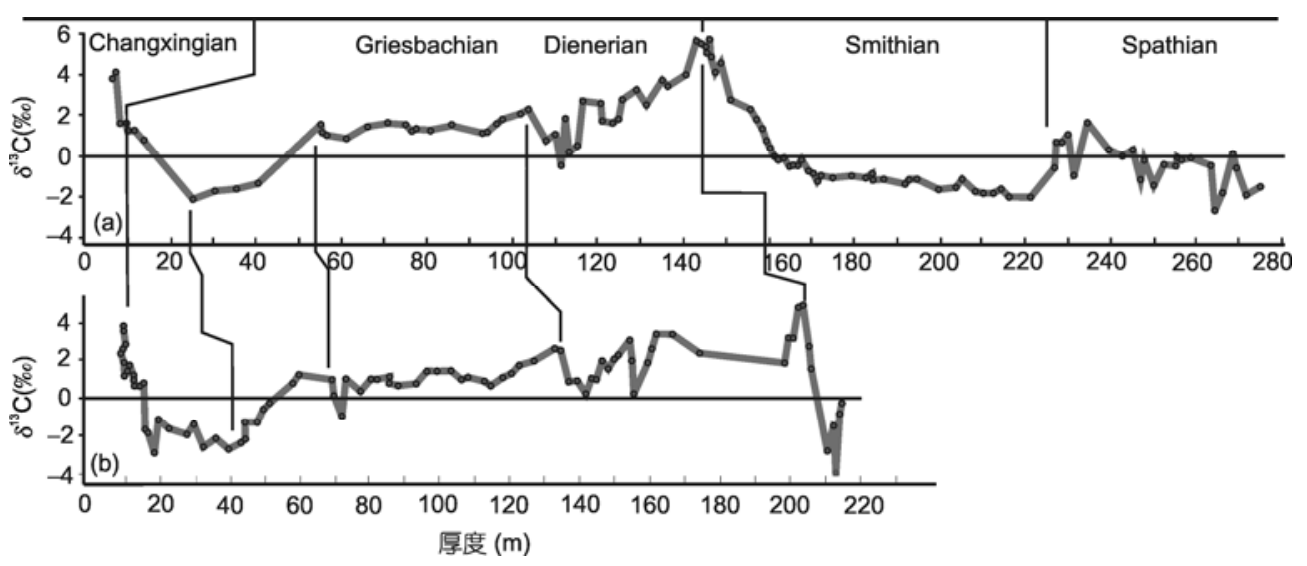

图 3 意大利北部晚二叠世-早三叠世海相碳酸盐碳同位素演化曲线(据文献[12])

(a) Uomo 剖面; (b) Pufels 剖面

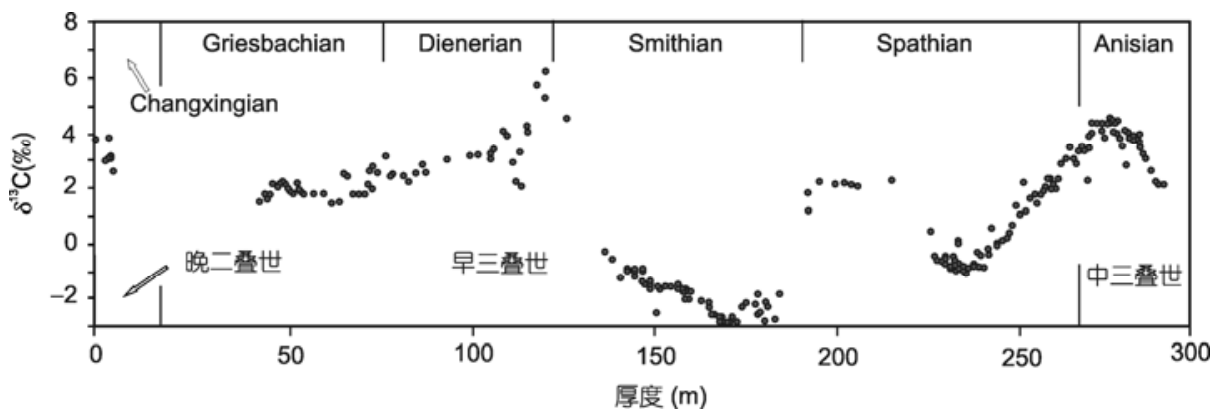

图 4 中国贵州关刀剖面海相碳酸盐碳同位素演化曲线(据文献[13])

严重的生物灭绝事件之后的生态重建时间段而备受 人们关注，但对该地史时期记录全球碳循环的海相 碳酸盐的碳同位素组成及其演化的研究仍然比较薄 弱, 显著落后于显生宙的其他时间段, 这显然与该时
间段样品获取较为困难有关. 目前全球范围内早三 叠世碳同位素组成研究问题的关键包括如下两个方 面: (1) 为什么早三叠世海水碳同位素组成不像其他 地质时期那样具有较好的全球一致性，是成岩蚀变 
的影响还是地方性事件的影响? 虽然下扬子地区的 样品具有较高的锰含量、较低的锶含量和较高的锰/ 锶比值, 但氧、碳同位素的相关性仍然说明其较好的 代表了海水 ${ }^{[5,6]}$, 同时就我们多年的研究经验而论, 由于碳的同位素组成对温度的不敏感以及成岩流体 中碳的水/岩比值很低等原因, 一般说来, 多数沉积 碳酸盐对海水的碳同位素组成都有较好的代表性. 如果是这样, 我们很难理解不同地方早三叠世海水 碳同位素组成的差别, 如果地方性事件的影响(如沉 积相) 是主要的, 那么海相碳酸盐碳同位素组成在地 层学中的潜在价值将会受到挑战; (2) 早三叠世碳酸 盐的碳同位素组成具有非常大的变化范围 $\left(\delta^{13} \mathrm{C}\right.$ 的变 化幅度可达 $10 \%$ ), 并在短时间内多次大幅度波动, 我们需要知道的是, 早三叠世碳酸盐的这种大幅度 波动是全球性的还是地方性的, 无论是全球性的还 是地方性的, 我们都想知道其控制机制是什么, 与二 叠纪末期发生的生物群体灭绝事件有何关系.

与世界其他地方相比, 中国早三叠世海相碳酸 盐岩相对发育, 具有进行古海洋学研究的良好条件, 但一些地区(尤其是上扬子地区)的年代地层学等基 础研究较为薄弱, 样品对海水信息的代表性问题也 需要作进一步的研究, 已获得的数据仍然难以进行 全球对比, 沉积盆地内部或盆地之间的对比也比较 困难, 因而早三叠世海相碳酸盐岩的碳同位素研究 仍然任重而道远.

\section{1 样品采集地点、地层和研究方法}

本文涉及的样品均采自四川盆地东部, 包括重 庆中梁山剖面、北碚剖面和四川华菳市/邻水县的仰 天窝剖面(图 5). 重庆中梁山剖面主要涉及二叠系长 兴组和二叠系-三叠系过渡带的样品; 华菳市/邻水县 仰天窝剖面主要涉及三叠系飞仙关组、嘉陵江组和雷 口坡组的样品; 北碚剖面主要涉及嘉陵江组第 IV 段 (简称嘉 IV 段, 全文中类似情况作相同处理) 的少量 样品, 以补充作为蒸发盐/白云岩层的嘉 IV 段样品的 不足. 这三个地表剖面都位于华菳山帚状褶皱带东 北部. 河坝 1 井主要用以补充同样作为蒸发盐/白云 岩层的嘉 II 段地表样品的不足, 该井位于华菳山帚 状褶皱带东北部与大巴山褶皱带的接合部(图 5).

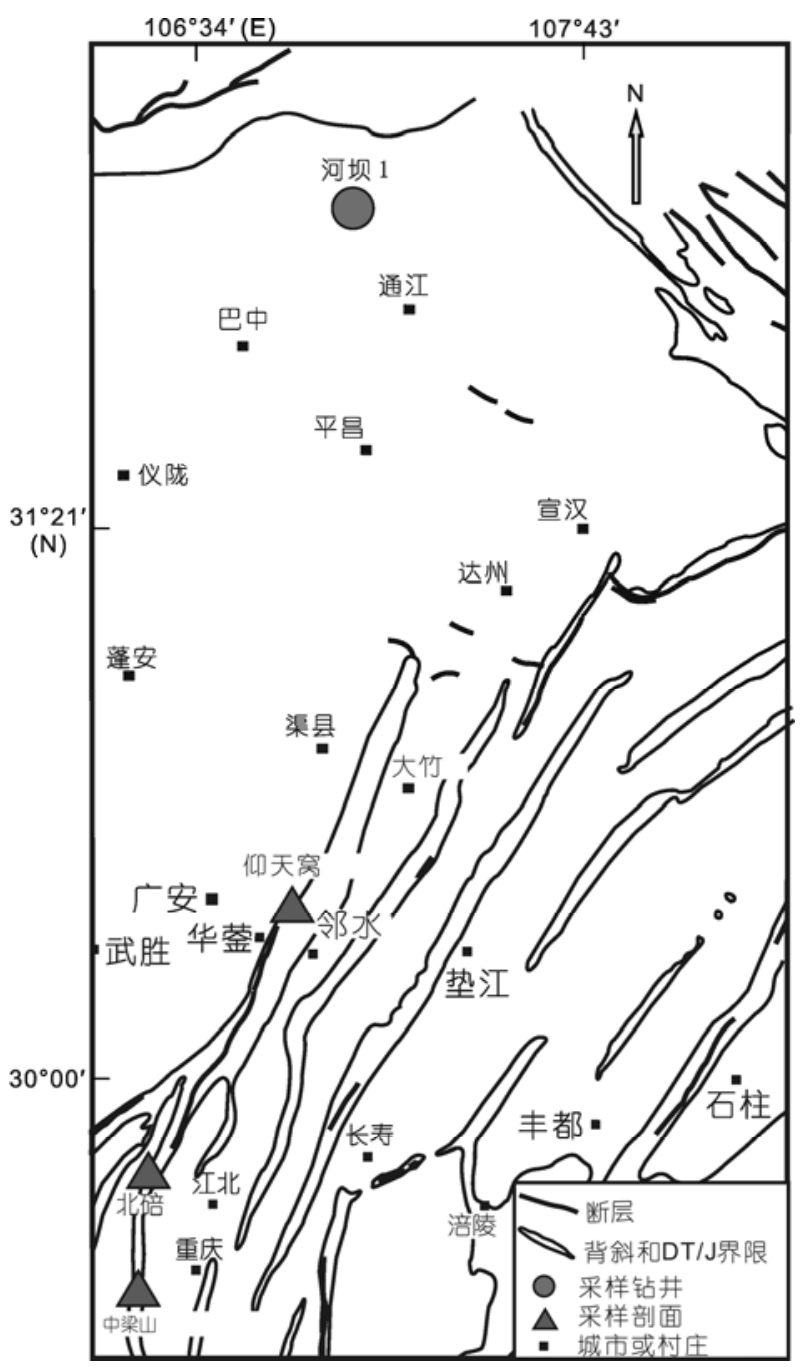

图 5 样品采集剖面和钻井的位置图 底图源自四川省 $1 / 100$ 万地质图 ${ }^{1)}$

由于样品采自不同的钻井或剖面, 需要对样品 的厚度/深度的处理进行必要的说明: (1) 剖面变换在 可识别的地质界线处, 如二叠系-三叠系处为中梁山 剖面和仰天窝剖面的切换, 厚度从中梁山剖面累加; (2) 嘉 II 段的样品主要来自河坝 1 井, 将该井嘉 II 段 顶底与仰天窝剖面对接, 按厚度比例计算将河坝 1 井 嘉 II 段井深换算成仰天窝剖面的厚度, 这样可同时 使用仰天窝剖面和河坝 1 井嘉 II 段的样品, 这里假定 了在嘉 II 段对应的时间中, 各剖面/钻井内部沉积速 率是不变的, 这对于嘉 II 段这样的小范围时间间隔 来说, 这种假定是可以接受的; (3) 北碚剖面的少量

1）四川省地质矿产局. 四川省 1/100 万地质图. 1991 
嘉 IV 段样品插入仰天窝剖面也采用了相同的办法. 尽管如此，同一地层段我们仍然主要使用同一剖面 的样品, 以避免这种插入方式对曲线形态的歪曲, 同 时在有关图件中插入的其他剖面的样品我们用不同 符号标记, 以示区别.

作为剖面中最为关键的地质界线, 即二叠纪-三 叠纪界线, 是很容易在野外识别的直观界线(图 6). 二 叠系长兴组顶部是含燧石结核的含生物碎屑微晶灰 岩, 三叠系飞仙关组是紫红色泥质微晶灰岩, 其间有 厚约 $1 \mathrm{~m}$ 的过渡带, 存在至少 3 层灰白色粘土岩. 前人 的研究表明, 该粘土岩的粘土矿物主要是规则混层伊 利石/蒙皇石 ${ }^{[14]}$, 并含有较多的自形锆石、自形六方双 锥石英、火山球粒等物质 ${ }^{[15]}$, 因而它们和华南其他地 方(如浙江长兴煤山和广元上寺)报道的界线粘土岩的 成因一样, 是同期火山物质蚀变产物, 并具有等时性.

样品主要有两种类型, 即石灰岩和白云岩, 也包 括成分上的过渡类型, 样品成分上的这些变化通过 $\mathrm{MgO}$ 和 $\mathrm{CaO}$ 的相对含量来表征(表 1). 从结构上说, 石灰岩均具微晶-泥晶结构, 白云岩则包括微晶结构 和粉-细晶结构两种类型. 所有用于同位素分析的样 品都进行了薄片鉴定(包括铁氭化钾染色分析)和阴 极发光检测, 大多数样品都不具阴极发光或只具很 弱的阴极发光, 铁氰化钾染色分析表明样品的这种 弱(或无)阴极发光性主要是由于其较低的 $\mathrm{Mn}$ 含量造 成的 ${ }^{[16]}$. 借助双目镜对用于同位素分析的样品进行 了细致的分拣, 尽可能地回避了方解石脉和亮晶方 解石胶结物. 样品经挑选后粉碎至 200 目, 缩分成三
份, 除一份留作备用外, 另外两份分别用作 $\mathrm{CaO}$, $\mathrm{MgO}, \mathrm{Mn}$ 和 $\mathrm{Sr}$ 含量分析和同位素分析(包括碳氧同位 素分析和锶同位素分析).

碳、氧同位素分析主要由中国石油西南油气田分 公司勘探开发研究院完成, Finigan MAT 252 气体同位 素质谱仪, GBW04406 标样的分析误差为 $0.01 \%$; $\mathrm{CaO}$, $\mathrm{MgO}, \mathrm{Mn}$ 和 $\mathrm{Sr}$ 含量分析由四川省地质矿产局华阳地 矿检测中心完成. $\mathrm{CaO}$ 和 $\mathrm{MgO}$ 含量由常规化学分析方 法测试, 检测限为 $1 \%$, 误差为 $5 \%$; $\mathrm{Mn}$ 和 $\mathrm{Sr}$ 含量由原 子吸收光度法测试, 检测限分别为 5 和 $42 \mathrm{ppm}$, 误差 分别为 $13 \%$ 和 $14 \%$; 阴极发光分析由成都理工大学油 气藏地质及开发工程国家重点实验室完成, 使用剑桥 仪器公司 CL8200MK5 阴极发光仪(配以 Leica 偏光显 微镜), 测试条件选择束电压 $12 \mathrm{kV}$, 束电流 $300 \mathrm{uA}$.

\section{2 分析结果及同位素组成对海水代表性的 评估}

四川盆地东部晚二叠-早三叠世海相碳酸盐的 碳、氧同位素分析结果列于表 1 中, 表中共涉及 116 个样品的碳、氧同位素组成, 其中绝大多数样品(110 个)都同时给出了相应的 $\mathrm{CaO}, \mathrm{MgO}, \mathrm{Mn}$ 和 $\mathrm{Sr}$ 含量和 $\mathrm{Mn} / \mathrm{Sr}$ 比值, 以帮助我们理解样品的矿物组成并评价 其对海水的代表性. 地表剖面的大部分样品(共计 73 个)都进行了锶同位素分析, 相应的锶同位素数据已 公布 ${ }^{[17,18]}$, 为了保持这些样品各种地球化学信息的 完整性，表 1 中也将其同时列出.

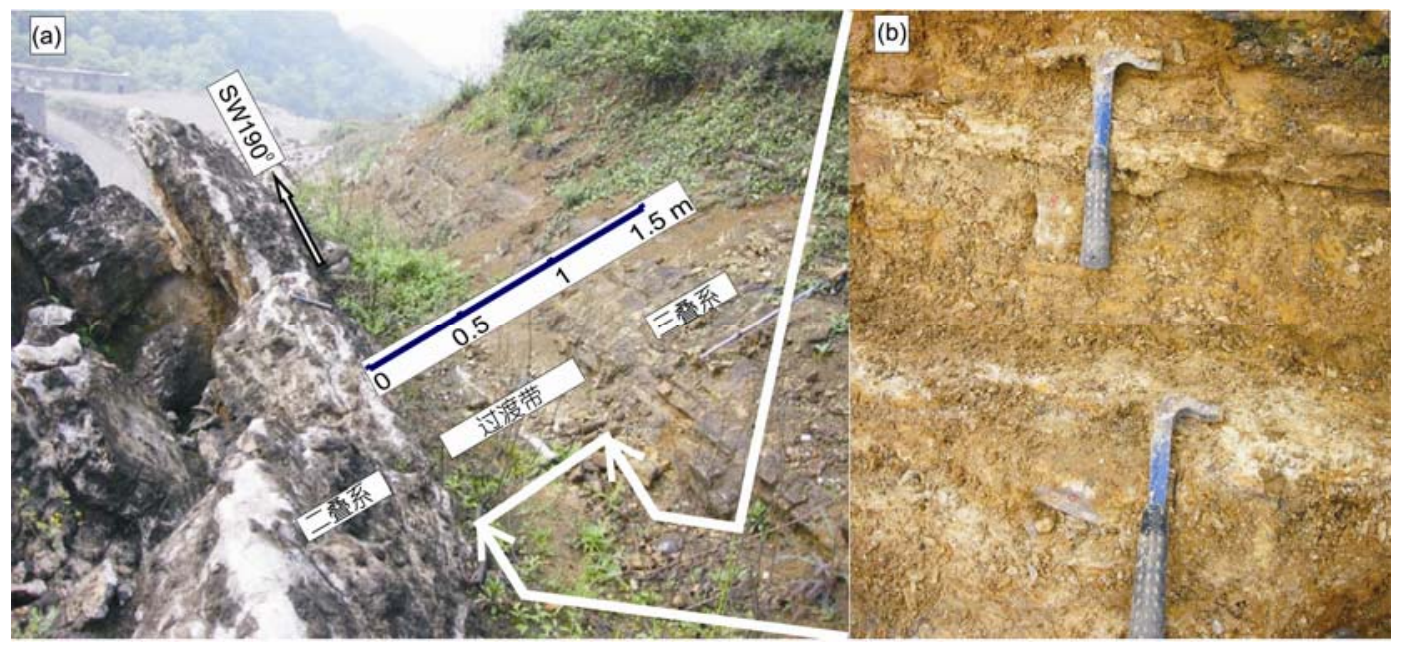

图 6 重庆中梁山二叠纪-三叠纪界线

(a) 显示二叠纪-三叠纪界线处岩性急剧变化; (b) 二叠纪-三叠纪界线处(二叠纪-三叠纪过渡带)的放大, 显示过渡带存在至少三层灰白色粘土岩 
表 1 四川盆地东部晚二叠世-早三叠世海相碳酸盐碳、氧同位素组成及相关数据

\begin{tabular}{|c|c|c|c|c|c|c|c|c|c|c|c|}
\hline 剖面/钻井 & 地层(组/段) & 累积厚度(m) & $\mathrm{CaO}(\%)$ & $\mathrm{MgO}(\%)$ & $\mathrm{Mn}(\mathrm{ppm})$ & $\mathrm{Sr}(\mathrm{ppm})$ & $\mathrm{Mn} / \mathrm{Sr}$ & $\delta^{13} \mathrm{C}(\% o) \delta^{13} \mathrm{C}(\% o)^{\mathrm{a})}$ & $\delta^{18} \mathrm{O}(\%)$ & ${ }^{87} \mathrm{Sr} /{ }^{86} \mathrm{Sr}$ & 备注 \\
\hline 中梁山 & 长兴组 & 1.0 & & & & & & 4.05 & -6.34 & & \\
\hline 中梁山 & 长兴组 & 7.0 & & & & & & 3.77 & -6.73 & & \\
\hline 中梁山 & 长兴组 & 15.5 & & & & & & 4.51 & -7.24 & & \\
\hline 中梁山 & 长兴组 & 17.0 & 44.02 & 1.64 & 78.0 & 1278.0 & 0.06 & 3.99 & -6.22 & 0.707061 & \\
\hline 中梁山 & 长兴组 & 27.0 & 53.58 & 1.10 & 105.0 & 1620.0 & 0.06 & 3.95 & -5.34 & 0.707011 & \\
\hline 中梁山 & 长兴组 & 31.0 & & & & & & 3.50 & -6.90 & & \\
\hline 中梁山 & 长兴组 & 36.0 & 52.00 & 3.55 & 36.0 & 1525.4 & 0.02 & 3.80 & -6.31 & & \\
\hline 中梁山 & 长兴组 & 37.0 & 54.86 & 0.51 & 52.0 & 1659.0 & 0.03 & 4.40 & -6.63 & 0.707053 & \\
\hline 中梁山 & 长兴组 & 43.5 & 54.85 & 0.75 & 35.4 & 1875.6 & 0.02 & 3.35 & -6.91 & & \\
\hline 中梁山 & 长兴组 & 46.0 & 57.48 & 0.43 & 27.9 & 1592.7 & 0.02 & 3.22 & -5.85 & & \\
\hline 中梁山 & 长兴组 & 49.0 & & & & & & 3.20 & -6.93 & & \\
\hline 中梁山 & 长兴组 & 50.0 & 51.82 & 2.70 & 45.0 & 1000.0 & 0.05 & 3.69 & -7.07 & 0.707075 & \\
\hline 中梁山 & 长兴组 & 54.8 & 53.77 & 0.28 & 39.0 & 1045.0 & 0.04 & 2.66 & -5.74 & 0.707081 & \\
\hline 中梁山 & 长兴组 & 55.6 & 50.47 & 0.28 & 67.0 & 1650.0 & 0.04 & 2.61 & -6.13 & 0.707105 & \\
\hline 中梁山 & 长兴组 & 56.4 & 45.83 & 0.56 & 77.0 & 1410.0 & 0.05 & 2.29 & -6.26 & 0.707048 & \\
\hline 中梁山 & 长兴组 & 57.2 & 44.64 & 0.38 & 282.0 & 1425.0 & 0.20 & 1.51 & -7.29 & 0.707111 & \\
\hline 中梁山 & $\mathrm{P} / \mathrm{T}$ 过渡 & 58.2 & 48.61 & 0.18 & 369.0 & 1550.0 & 0.24 & 1.09 & -7.67 & 0.70713 & \\
\hline 中梁山 & $\mathrm{P} / \mathrm{T}$ 过渡 & 58.4 & 50.47 & 0.48 & 479.0 & 1130.0 & 0.42 & -0.94 & -7.37 & 0.707123 & \\
\hline 中梁山 & $\mathrm{P} / \mathrm{T}$ 过渡 & 58.5 & 48.22 & 0.66 & 471.0 & 980.0 & 0.48 & 0.00 & -7.04 & 0.707122 & \\
\hline 中梁山 & $\mathrm{P} / \mathrm{T}$ 过渡 & 58.5 & 0.63 & 0.04 & 485.1 & 92.2 & 5.26 & 2.62 & -8.40 & & 剔除 \\
\hline 中梁山 & $\mathrm{P} / \mathrm{T}$ 过渡 & 58.8 & 27.82 & 0.76 & 393.0 & 625.0 & 0.63 & 0.01 & -7.73 & 0.707189 & \\
\hline 中梁山 & $\mathrm{P} / \mathrm{T}$ 过渡 & 59.0 & 43.31 & 0.28 & 628.0 & 910.0 & 0.69 & -0.26 & -7.53 & 0.707141 & \\
\hline 中梁山 & $\mathrm{P} / \mathrm{T}$ 过渡 & 59.1 & 39.60 & 0.56 & 670.0 & 1410.0 & 0.48 & -0.43 & -9.86 & 0.707176 & \\
\hline 中梁山 & $\mathrm{P} / \mathrm{T}$ 过渡 & 60.6 & 31.26 & 2.95 & 565.0 & 510.0 & 1.11 & -1.26 & -7.74 & 0.707085 & \\
\hline 仰天窝 & 飞仙关组 & 61.6 & 44.10 & 1.72 & 2354.0 & 291.0 & 8.09 & -0.04 & -5.57 & 0.707227 & 剔除 \\
\hline 仰天窝 & 飞仙关组 & 62.9 & 19.31 & 4.01 & 1367.0 & 470.0 & 2.91 & -3.04 & -6.76 & 0.707418 & 剔除 \\
\hline 仰天窝 & 飞仙关组 & 65.7 & 36.98 & 3.00 & 108.0 & 920.0 & 0.12 & -1.25 & -6.11 & 0.70721 & \\
\hline 仰天窝 & 飞仙关组 & 68.2 & 35.82 & 1.84 & 794.0 & 900.0 & 0.88 & -1.59 & -5.95 & 0.707216 & \\
\hline 仰天窝 & 飞仙关组 & 73.4 & 33.02 & 2.34 & 635.0 & 1035.0 & 0.61 & -1.08 & -6.07 & 0.707253 & \\
\hline 仰天窝 & 飞仙关组 & 77.4 & 35.82 & 0.99 & 999.0 & 1120.0 & 0.89 & -1.05 & -6.25 & 0.707219 & \\
\hline 仰天窝 & 飞仙关组 & 93.4 & 33.02 & 2.67 & 523.0 & 1360.0 & 0.38 & 0.12 & -6.04 & 0.707217 & \\
\hline 中梁山 & 飞仙关组 & 104.0 & & & & & & -1.14 & -6.76 & & \\
\hline 仰天窝 & 飞仙关组 & 123.9 & 39.77 & 2.01 & 418.0 & 1396.0 & 0.30 & 0.49 & -6.19 & 0.70719 & \\
\hline 仰天窝 & 飞仙关组 & 143.9 & 47.45 & 1.51 & 182.0 & 2415.0 & 0.08 & 0.30 & -5.85 & 0.707211 & \\
\hline 仰天窝 & 飞仙关组 & 167.0 & 50.23 & 0.50 & 325.0 & 1015.0 & 0.32 & 1.05 & -5.39 & 0.707245 & \\
\hline 仰天窝 & 飞仙关组 & 185.9 & 50.47 & 0.83 & 97.0 & 625.0 & 0.16 & 1.81 & -5.05 & 0.707277 & \\
\hline 仰天窝 & 飞仙关组 & 211.3 & 52.56 & 0.50 & 101.0 & 985.0 & 0.10 & 2.29 & -5.62 & 0.707265 & \\
\hline 仰天窝 & 飞仙关组 & 231.0 & 43.95 & 1.51 & 259.0 & 765.0 & 0.34 & 1.98 & -5.63 & 0.707302 & \\
\hline 仰天窝 & 飞仙关组 & 252.7 & 50.01 & 0.66 & 236.0 & 815.0 & 0.29 & 2.42 & -5.82 & 0.70729 & \\
\hline 仰天窝 & 飞仙关组 & 269.7 & 50.23 & 1.18 & 112.0 & 875.0 & 0.13 & 2.33 & -5.40 & 0.707295 & \\
\hline 仰天窝 & 飞仙关组 & 294.7 & 37.68 & 3.00 & 387.0 & 705.0 & 0.55 & 1.74 & -5.29 & 0.707308 & \\
\hline 仰天窝 & 飞仙关组 & 319.2 & 46.97 & 1.34 & 329.0 & 1050.0 & 0.31 & 2.15 & -5.69 & 0.707309 & \\
\hline 仰天窝 & 飞仙关组 & 333.7 & 11.87 & 2.67 & 968.0 & 250.0 & 3.87 & -2.61 & -6.22 & 0.707667 & 剔除 \\
\hline 仰天窝 & 飞仙关组 & 349.7 & 24.18 & 2.17 & 848.0 & 310.0 & 2.74 & -0.14 & -5.79 & 0.707516 & 剔除 \\
\hline 仰天窝 & 飞仙关组 & 379.8 & 51.40 & 0.73 & 349.0 & 480.0 & 0.73 & 0.94 & -5.59 & 0.707327 & \\
\hline 仰天窝 & 飞仙关组 & 380.1 & 54.13 & 0.90 & 290.0 & 2613.0 & 0.11 & 1.19 & -5.21 & 0.707297 & \\
\hline 仰天窝 & 飞仙关组 & 380.3 & 52.08 & 1.14 & 256.0 & 602.0 & 0.43 & 1.31 & -5.58 & 0.707316 & \\
\hline 仰天窝 & 飞仙关组 & 380.4 & 51.40 & 2.04 & 267.0 & 603.0 & 0.44 & 1.29 & -5.43 & 0.707346 & \\
\hline
\end{tabular}


黄思静等: 早三叠世海水的碳同位素组成与演化

\begin{tabular}{|c|c|c|c|c|c|c|c|c|c|c|c|c|}
\hline 剖面/钻井 & 地层(组/段) & 累积厚度 $(\mathrm{m})$ & $\mathrm{CaO}(\%)$ & $\mathrm{MgO}(\%)$ & $\mathrm{Mn}(\mathrm{ppm})$ & $\mathrm{Sr}(\mathrm{ppm})$ & $\mathrm{Mn} / \mathrm{Sr}$ & $\delta^{13} \mathrm{C}(\% o)$ & $\delta^{13} \mathrm{C}(\% \circ)^{\mathrm{a})}$ & $\delta^{18} \mathrm{O}(\% \circ)$ & ${ }^{87} \mathrm{Sr} /{ }^{86} \mathrm{Sr}$ & 备注 \\
\hline 仰天窝 & 飞仙关组 & 380.6 & 53.68 & 1.39 & 225.0 & 592.0 & 0.38 & 1.19 & & -5.51 & 0.707331 & \\
\hline 仰天窝 & 飞仙关组 & 381.0 & 50.48 & 1.31 & 248.0 & 485.0 & 0.51 & 1.48 & & -5.81 & 0.707312 & \\
\hline 仰天窝 & 飞仙关组 & 381.4 & 54.36 & 3.43 & 294.0 & 417.0 & 0.71 & 1.41 & & -5.86 & 0.707327 & \\
\hline 仰天窝 & 飞仙关组 & 385.2 & 53.03 & 0.50 & 108.0 & 655.0 & 0.16 & 1.30 & & -5.64 & 0.707373 & \\
\hline 仰天窝 & 飞仙关组 & 424.7 & 53.72 & 1.34 & 8.0 & 530.0 & 0.02 & 1.28 & & -5.47 & 0.707474 & \\
\hline 仰天窝 & 飞仙关组 & 441.2 & 52.79 & 0.83 & 50.0 & 1310.0 & 0.04 & 2.22 & & -5.69 & 0.707514 & \\
\hline 仰天窝 & 飞仙关组 & 465.2 & 54.66 & 1.51 & 23.0 & 560.0 & 0.04 & 2.99 & & -5.72 & 0.707506 & \\
\hline 仰天窝 & 飞仙关组 & 489.2 & 54.66 & 0.17 & 8.0 & 745.0 & 0.01 & 3.05 & & -5.74 & 0.707554 & \\
\hline 仰天窝 & 飞仙关组 & 510.2 & 49.31 & 0.99 & 182.0 & 750.0 & 0.24 & 3.76 & & -5.66 & 0.707614 & \\
\hline 仰天窝 & 飞仙关组 & 529.9 & 51.40 & 0.33 & 85.0 & 735.0 & 0.12 & 3.45 & & -5.47 & 0.707614 & \\
\hline 仰天窝 & 飞仙关组 & 562.9 & 49.30 & 0.83 & 259.0 & 620.0 & 0.42 & 3.92 & & -5.67 & 0.707675 & \\
\hline 仰天窝 & 嘉 I 段 & 577.0 & 45.81 & 1.51 & 325.0 & 270.0 & 1.20 & 4.88 & & -5.26 & 0.707749 & \\
\hline 仰天窝 & 嘉 1 段 & 595.0 & 53.49 & 0.33 & 97.0 & 665.0 & 0.15 & 4.69 & & -5.38 & 0.707753 & \\
\hline 仰天窝 & 嘉 1 段 & 619.0 & 50.01 & 1.34 & 77.0 & 525.0 & 0.15 & 2.28 & & -5.55 & 0.707788 & \\
\hline 仰天窝 & 嘉 1 段 & 638.0 & 52.56 & 0.50 & 35.0 & 910.0 & 0.04 & 0.74 & & -5.62 & 0.707785 & \\
\hline 仰天窝 & 嘉 1 段 & 658.0 & 53.72 & 0.33 & 39.0 & 1190.0 & 0.03 & -0.10 & & -5.83 & 0.707799 & \\
\hline 河坝 1 & 嘉 II 段 & 680.8 & 26.13 & 18.64 & 296.7 & 1413.0 & 0.21 & -0.49 & & -3.98 & & \\
\hline 河坝 1 & 嘉 II 段 & 685.4 & 26.33 & 19.14 & 263.3 & 117.5 & 2.24 & -0.06 & & -3.67 & & 剔除 \\
\hline 河坝 1 & 嘉 II 段 & 692.2 & 28.69 & 18.13 & 137.9 & 480.2 & 0.29 & 1.08 & & -3.71 & & \\
\hline 河坝 1 & 嘉 II 段 & 698.1 & 26.91 & 18.58 & 187.4 & 305.5 & 0.61 & 2.08 & & -3.88 & & \\
\hline 河坝 1 & 嘉 II 段 & 701.8 & 23.43 & 18.03 & 167.2 & 151.4 & 1.10 & 0.84 & & -4.12 & & \\
\hline 河坝 1 & 嘉 II 段 & 707.9 & 26.37 & 18.89 & 154.3 & 163.7 & 0.94 & 1.49 & & -4.35 & & \\
\hline 仰天窝 & 嘉 II 段 & 710.5 & 37.21 & 7.86 & 174.0 & 430.0 & 0.40 & -1.47 & & -4.41 & 0.707996 & \\
\hline 河坝 1 & 嘉 II 段 & 710.9 & 30.19 & 15.82 & 132.5 & 935.2 & 0.14 & 1.61 & & -4.12 & & \\
\hline 河坝 1 & 嘉 II 段 & 739.1 & 6.54 & 10.30 & 286.6 & 347.8 & 0.82 & -1.07 & & -3.24 & & \\
\hline 仰天窝 & 嘉 II 段 & 750.5 & 34.42 & 17.54 & 89.0 & 120.0 & 0.74 & 2.94 & & -3.62 & 0.708339 & \\
\hline 河坝 1 & 嘉 II 段 & 752.0 & 34.10 & 16.90 & 32.0 & 253.4 & 0.13 & 7.36 & & -3.92 & & \\
\hline 河坝 1 & 嘉 II 段 & 753.4 & 33.46 & 19.83 & 70.8 & 154.4 & 0.46 & 6.32 & 8.01 & -4.16 & & \\
\hline 河坝 1 & 嘉 II 段 & 754.0 & 29.71 & 20.56 & 27.1 & 113.6 & 0.24 & 6.84 & 7.15 & -3.59 & & \\
\hline 河坝 1 & 嘉 II 段 & 755.1 & 30.14 & 20.91 & 26.1 & 87.2 & 0.30 & 7.02 & 7.32 & -2.79 & & \\
\hline 河坝 1 & 嘉 II 段 & 756.5 & 34.91 & 18.01 & 13.1 & 367.4 & 0.04 & 2.52 & 5.57 & -4.36 & & \\
\hline 河坝 1 & 嘉 II 段 & 759.0 & 29.12 & 20.51 & 29.5 & 86.6 & 0.34 & 6.50 & 6.68 & -3.14 & & \\
\hline 河坝 1 & 嘉 II 段 & 759.0 & 32.62 & 20.02 & 58.5 & 104.3 & 0.56 & 5.72 & 7.07 & -4.02 & & \\
\hline 河坝 1 & 嘉 II 段 & 759.0 & 32.62 & 20.02 & 58.5 & 104.3 & 0.56 & 5.72 & 7.07 & -4.02 & & \\
\hline 河坝 1 & 嘉 II 段 & 759.6 & 29.89 & 20.73 & 22.8 & 95.1 & 0.24 & 6.33 & 6.63 & -3.31 & & \\
\hline 河坝 1 & 嘉 II 段 & 760.3 & 31.94 & 19.23 & 27.9 & 193.9 & 0.14 & 5.44 & 6.91 & -4.21 & & \\
\hline 河坝 1 & 嘉 II 段 & 762.2 & 30.02 & 21.01 & 23.7 & 97.4 & 0.24 & 5.99 & 6.22 & -3.21 & & \\
\hline 河坝 1 & 嘉 II 段 & 763.4 & 30.48 & 20.56 & 17.7 & 126.3 & 0.14 & 5.76 & 6.28 & -3.50 & & \\
\hline 河坝 1 & 嘉 II 段 & 763.4 & 30.78 & 20.64 & 11.9 & 140.4 & 0.08 & 5.62 & 6.19 & -3.40 & & \\
\hline 河坝 1 & 嘉 II 段 & 763.4 & 30.96 & 20.26 & 27.6 & 156.2 & 0.18 & 5.35 & 6.12 & -3.81 & & \\
\hline 河坝 1 & 嘉 II 段 & 763.7 & 30.64 & 20.33 & 24.5 & 135.5 & 0.18 & 5.21 & 5.86 & -3.70 & & \\
\hline 河坝 1 & 嘉 II 段 & 763.7 & 32.96 & 18.98 & 22.2 & 224.3 & 0.10 & 4.23 & 6.14 & -3.90 & & \\
\hline 河坝 1 & 嘉 II 段 & 767.0 & 33.88 & 18.66 & 17.3 & 384.8 & 0.05 & 1.57 & 3.93 & -4.04 & & \\
\hline 仰天窝 & 嘉III段 & 767.5 & 38.13 & 0.83 & 46.0 & 210.0 & 0.22 & -0.38 & & -5.93 & 0.70813 & \\
\hline 仰天窝 & 嘉III段 & 783.5 & 53.03 & 1.51 & 31.0 & 1310.0 & 0.02 & 0.29 & & -5.17 & 0.70811 & \\
\hline 仰天窝 & 嘉III段 & 805.5 & 49.07 & 0.66 & 70.0 & 585.0 & 0.12 & 0.06 & & -5.42 & 0.708126 & \\
\hline 仰天窝 & 嘉III段 & 823.5 & 50.70 & 1.34 & 31.0 & 235.0 & 0.13 & -0.30 & & -5.57 & 0.708126 & \\
\hline 仰天窝 & 嘉III段 & 853.5 & 51.17 & 0.66 & 39.0 & 770.0 & 0.05 & -0.27 & & -5.40 & 0.708158 & \\
\hline 仰天窝 & 嘉IV段 & 888.5 & 30.46 & 19.05 & 58.0 & 35.0 & 1.66 & -1.34 & & -3.50 & 0.708428 & \\
\hline
\end{tabular}

1514 


\begin{tabular}{|c|c|c|c|c|c|c|c|c|c|c|c|c|}
\hline 剖面/钻井 & 地层(组/段) & 累积厚度 $(\mathrm{m})$ & $\mathrm{CaO}(\%)$ & $\mathrm{MgO}(\%)$ & $\mathrm{Mn}(\mathrm{ppm})$ & $\mathrm{Sr}(\mathrm{ppm})$ & $\mathrm{Mn} / \mathrm{Sr}$ & $\delta^{13} \mathrm{C}(\% \circ)$ & $\delta^{13} \mathrm{C}(\% \circ)^{\mathrm{a})}$ & $\delta^{18} \mathrm{O}(\% o)$ & ${ }^{87} \mathrm{Sr} /{ }^{86} \mathrm{Sr}$ & 备注 \\
\hline 仰天窝 & $\begin{array}{l}\text { 嘉IV段 } \\
\end{array}$ & 908.4 & 28.38 & 19.39 & 50.0 & 90.0 & 0.56 & 0.03 & & -3.71 & 0.708322 & \\
\hline 仰天窝 & 嘉IV段 & 939.4 & 31.86 & 18.89 & 58.0 & 100.0 & 0.58 & 2.23 & & -4.70 & 0.708286 & \\
\hline 仰天窝 & 嘉IV段 & 950.8 & 28.66 & 21.23 & 122.9 & 88.9 & 1.38 & -0.92 & & -5.11 & & \\
\hline 北碚 & 嘉IV段 & 951.0 & 31.01 & 20.75 & 86.6 & 77.5 & 1.12 & 0.38 & & -3.79 & & \\
\hline 仰天窝 & 嘉IV段 & 954.4 & 46.75 & 0.17 & 4.0 & 1015.0 & 0.00 & 1.57 & & -4.87 & 0.708208 & \\
\hline 北碚 & 嘉IV段 & 961.5 & 32.57 & 20.12 & 85.7 & 93.2 & 0.92 & -0.46 & & -3.94 & & \\
\hline 仰天窝 & 嘉IV段 & 964.0 & 30.44 & 24.24 & 100.2 & 65.7 & 1.53 & -1.72 & & -3.99 & & \\
\hline 中梁山 & 嘉IV段 & 971.9 & 29.59 & 18.40 & 177.5 & 71.2 & 2.49 & -0.32 & & -5.75 & & 剔除 \\
\hline 仰天窝 & 嘉IV段 & 974.2 & 29.02 & 26.50 & 63.3 & 84.8 & 0.75 & 0.69 & & -3.56 & & \\
\hline 中梁山 & 嘉IV段 & 993.6 & 35.76 & 15.27 & 178.2 & 136.7 & 1.30 & -1.61 & & -7.23 & & \\
\hline 北碚 & 嘉IV段 & 1013.1 & 50.06 & 0.45 & 97.1 & 244.5 & 0.40 & -1.56 & & -8.35 & & \\
\hline 仰天窝 & 雷口坡组 & 1028.4 & 26.74 & 18.22 & 306.0 & 95.0 & 3.22 & -1.46 & & -0.88 & 0.709252 & 剔除 \\
\hline 仰天窝 & 雷口坡组 & 1045.4 & 30.00 & 18.22 & 151.0 & 75.0 & 2.01 & -1.00 & & -2.56 & 0.708222 & 剔除 \\
\hline 仰天窝 & 雷口坡组 & 1160.4 & 45.11 & 1.67 & 85.0 & 255.0 & 0.33 & -0.73 & & -3.75 & 0.708083 & \\
\hline 仰天窝 & 雷口坡组 & 1180.4 & 41.17 & 1.84 & 97.0 & 65.0 & 1.49 & -0.79 & & -3.73 & 0.70806 & \\
\hline 仰天窝 & 雷口坡组 & 1210.4 & 51.40 & 0.17 & 128.0 & 210.0 & 0.61 & 0.76 & & -5.52 & 0.707981 & \\
\hline 仰天窝 & 雷口坡组 & 1240.4 & 49.53 & 0.66 & 147.0 & 540.0 & 0.27 & 1.70 & & -6.62 & 0.708076 & \\
\hline 仰天窝 & 雷口坡组 & 1247.4 & 46.97 & 3.00 & 93.0 & 280.0 & 0.33 & 1.03 & & -4.84 & 0.708043 & \\
\hline 仰天窝 & 雷口坡组 & 1257.4 & 54.36 & 0.98 & 143.0 & 128.0 & 1.12 & 0.98 & & -7.72 & 0.707872 & \\
\hline
\end{tabular}

a) 校正的 $\delta^{13} \mathrm{C}$ 值, 见正文中讨论

\section{1 样品 $\mathrm{Mn}$ 和 $\mathrm{Sr}$ 含量及 $\mathrm{Mn} / \mathrm{Sr}$ 比值}

成岩蚀变可能影响碳酸盐样品同位素组成对海 水的代表性, 海相碳酸盐的成岩蚀变过程是一个锰 的获取过程和锶的丢失过程 ${ }^{[16,19]}$, 因而碳酸盐岩组 分的 $\mathrm{Mn}$ 和 $\mathrm{Sr}$ 含量与 $\mathrm{Mn} / \mathrm{Sr}$ 比值是人们用以判断其 成岩蚀变强度、或判断其对海水信息代表程度的有效 方法之一 ${ }^{[3,20,21]}$. 在表 1 所列的四川盆地东部四个剖 面(钻井)二叠纪末至早三叠世 116 个进行了碳同位素 分析的样品中, 有 110 个样品进行了 $\mathrm{Mn}$ 和 $\mathrm{Sr}$ 含量分 析, 其中 73 个样品的锶含量都在 $250 \mathrm{ppm}$ 以上, 最大 值为 $2613 \mathrm{ppm}$, 平均值为 $636 \mathrm{ppm}$, 锶含量小于 250 $\mathrm{ppm}$ 的样品主要为白云岩 $(\mathrm{MgO}$ 含量大于 $15 \%)$, 其较 低的锶含量在很大程度上与锶在白云石中较低的分 配系数有关 ${ }^{[22]}$, 并不能说明其不是海水中准同生交 代作用产物. 绝大多数样品的锶含量都显著大于 Derry 等 ${ }^{[23]}$ 建议的进行锶同位素地层学研究样品所需 $\mathrm{Sr}$ 含量的最小值 $(200 \mathrm{ppm})$, 因而从锶含量的角度来 说, 绝大多数样品都是进行同位素分析的良好材料. 尽管如此, 从样品的 $\mathrm{Mn} / \mathrm{Sr}$ 比值来说, 仍有 9 个样品 大于 2 , 如果按 Kaufman 等 ${ }^{[24,25]}$ 建议的海相碳酸盐锶 同位素地层学研究样品 $\mathrm{Mn} / \mathrm{Sr}$ 比值的上限为 2 3, 这 9 个样品的 $\delta^{13} \mathrm{C}$ 值只有参考意义, 在表 1 中我们将其
列为应剔除的样品, 在利用绝大多数数据勾绘碳同 位素演化趋势线中, 这 9 个样品中的大多数(6 个数 据)仍然和曲线的总体趋势一致, 但显著偏离演化曲 线的 3 个数据点都是 $\mathrm{Mn} / \mathrm{Sr}$ 比值大于 2 的样品(具有 较低的 $\delta^{13} \mathrm{C}$ 值, 因而成岩蚀变可能主要造成碳同位 素组成的降低), 说明用 $\mathrm{Mn} / \mathrm{Sr}$ 比值来剔除样品是合 理的. 总的说来, 四川盆地东部晚二叠世-早三叠世 海相碳酸盐具有较高的 $\mathrm{Sr}$ 含量和较低的 $\mathrm{Mn} / \mathrm{Sr}$ 比值, 其所经历的成岩蚀变较小, 对海水的代表性较好.

\section{2 样品的氧同位素组成}

碳酸盐的氧同位素组成在成岩作用过程中非常 容易变化 ${ }^{[10,26]}$. 四川盆地东部三个剖面(钻井)碳酸盐 岩的碳、氧同位素组成之间具有很差的相关性(图 $7(\mathrm{a}))$, 说明在成岩蚀变过程中 $\delta^{13} \mathrm{C}$ 值保持未变. 具有 较高白云石含量的碳酸盐岩可以通过较高的 $\delta^{18} \mathrm{O}$ 值 而被检测出来(图 7b), 但这些样品的 $\delta^{13} \mathrm{C}$ 值并没偏离, 它们与邻近的含白云石较低的样品相比具有类似的 $\delta^{13} \mathrm{C}$ 值. 样品碳、氧同位素的这种情况与 Horacek 等 ${ }^{[12]}$ 报道的位于意大利北部的海相碳酸盐的情况非常类 似，显示白云岩的碳同位素组成代表了海水，氧同位 素组成则与蒸发卤水有关. 

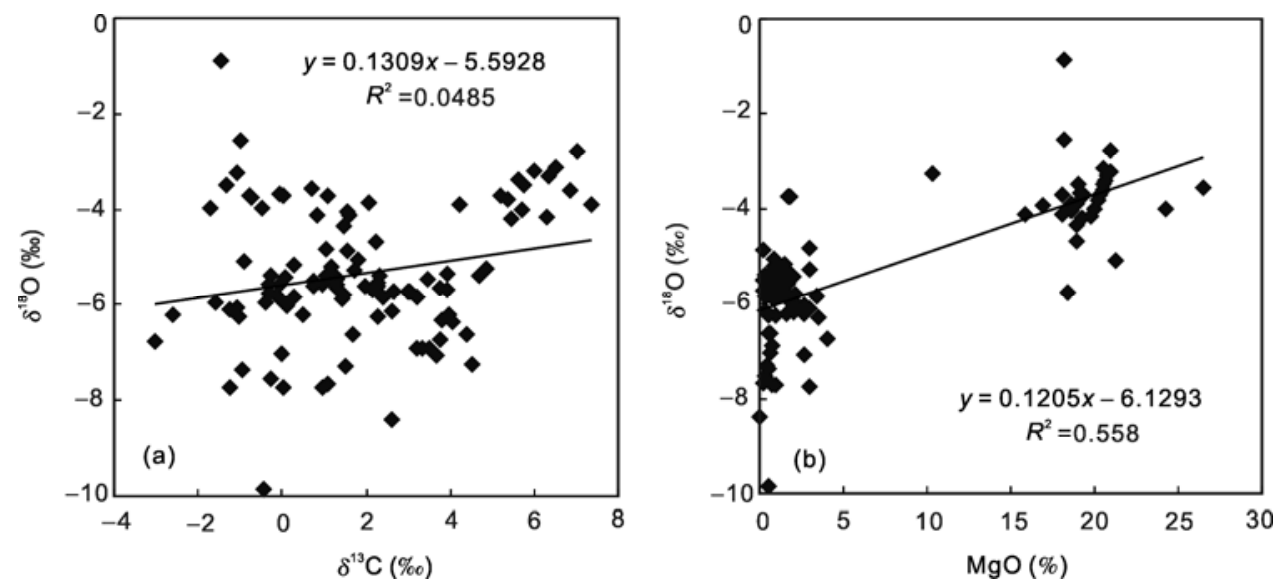

图 7 样品 $\delta^{18} \mathrm{O}$ 和 $\delta^{13} \mathrm{C}$ 值投点图(a)及 $\delta^{18} \mathrm{O}$ 值与 $\mathrm{MgO}$ 含量投点图(b)

与成岩过程中氧同位素组成的变化不同的是, 碳酸盐含量较高的全岩碳酸盐样品的碳同位素记录 大都没有在成岩过程中发生明显的变化, 因为岩石 中的碳储量远远多于溶于成岩流体中的碳. 碳酸盐 岩中碳同位素的成岩蚀变大多数都是导致 $\delta^{13} \mathrm{C}$ 值降 低, 这与氧同位素组成的变化是同步的. 只有在富有 机碳的岩石中细菌甲烷生成作用能够使碳酸盐的 $\delta^{13} \mathrm{C}$ 值升高 ${ }^{[27]}$. 采集样品的四川盆地东部四个剖面 (钻井)的岩石均贫有机碳而显著富碳酸盐, 所有这些 样品的碳同位素在成岩过程中都没有形成可检测到 的改变, 代表了原始海水的特征. 然而, 河坝 1 井可 能存在深埋藏过程中的热化学硫酸盐还原作用, 产 生的方解石可能降低全岩样品的 $\delta^{13} \mathrm{C}$ 值, 因而需要 进行必要的校正.

\section{3 部分样品的碳同位素校正}

需要进行碳同位素校正的样品来自河坝 1 井的 嘉陵江组第 2 段(嘉 II 段), 这是一个蒸发盐/白云岩地 层段, 两个地表剖面都因溶解作用垮塌而无法进行 完整的样品采集. 在井下采集的这些样品均为粉-细 晶白云岩(图 8), 且都不同程度地含有方解石, 已有 的研究表明这些白云石基本上是同期海水白云石化 作用造成的 ${ }^{[28]}$, 因而其碳同位素组成代表海水, 但分 布于晶体之间的方解石则与热化学硫酸盐还原作用 有关 ${ }^{[29]}$. 这些方解石的包裹体均一化温度主要分布 在 $110 \sim 140^{\circ} \mathrm{C}$ 之间, 在河坝 1 井深度范围很小的(只有 $5.8 \mathrm{~m}$, 以回避同位素组成的年代效应)间隔中, 岩石 的 $\delta^{13} \mathrm{C}$ 值、 $\delta^{18} \mathrm{O}$ 值与方解石含量显著相关(图 9). 利 用这种相关性, 我们可以求得当方解石在岩石中的
含量为 $100 \%$ 时, 样品的 $\delta^{13} \mathrm{C}$ 值为 $-14.1 \%$ o, $\delta^{18} \mathrm{O}$ 值为 $-11.04 \%$, 这些方解石所具有很低的 $\delta^{13} \mathrm{C}$ 和 $\delta^{18} \mathrm{O}$ 分 别说明其所具有的有机碳源和很高的沉淀温度, 它 们是热化学硫酸盐还原作用产物, 其碳同位素组成 不能代表海水. 根据岩石中方解石和白云石的相对 含量(从表 1 的 $\mathrm{CaO}$ 和 $\mathrm{MgO}$ 的相对含量计算)以及白 云石和方解石的 $\delta^{13} \mathrm{C}$ 值, 我们校正了这些样品的 $\delta^{13} \mathrm{C}$ 值, 结果列于表 1 中 (更为详细的讨论见文献 [29]).

\section{3 讨论}

\section{1 二叠纪-三叠纪界线和早-中三叠世界线的年龄 与对比}

(1) 二叠纪-三叠纪界线. 我国华南的二叠纪-三 叠纪界线是一个非常容易识别的直观界线(图 6), 也 是国际上认可的二叠纪-三叠纪界线, 界线粘土层为 同期火山物质蚀变产物. 前人 ${ }^{[30,31]}$ 曾多次利用 SHRIMP(高精度高灵敏度二次离子探针质谱仪, 以 下相同)测试了浙汇长兴煤山和四川广元上寺等地二 叠纪-三叠纪界线粘土层中锆石的 U-Pb 同位素年龄, 较新的数值为 $(252.6 \pm 0.2) \mathrm{Ma}^{[30]}$. 在碳同位素组成上, 界线附近存在人们所熟知的 $\delta^{13} \mathrm{C}$ 极小值 ${ }^{[10,11,32 \sim 35]}$, 本 研究也在界线附近检测到了这一极小值. 虽然图 10(a)和(b)给出了该界线不同的绝对年龄测试值(分别 为 252.6 和 $251.4 \mathrm{Ma}$ ), 但对有关的对比不会存在实质 性的影响.

(2) 早-中三叠世的界线. 我国西南地区早-中三 


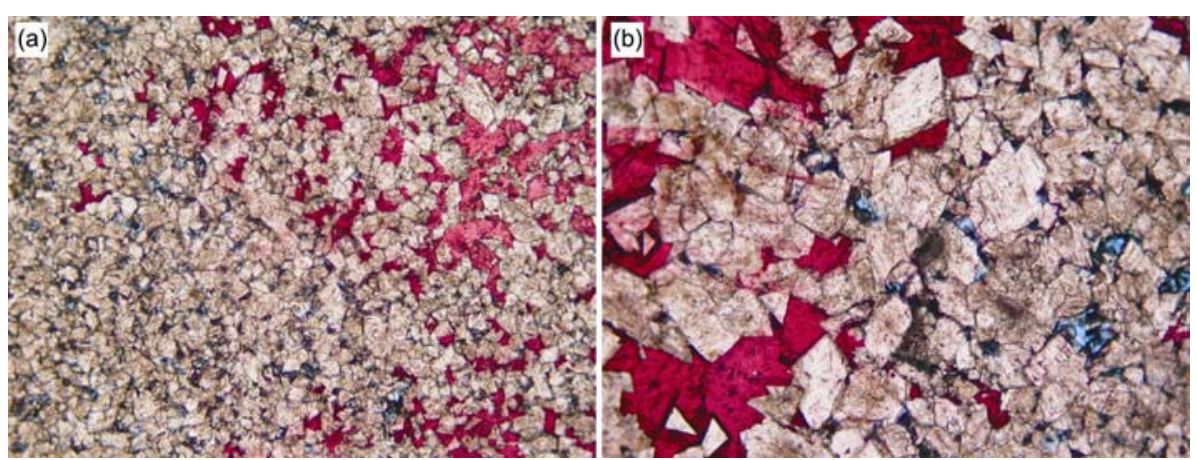

图 8 与热化学硫酸盐还原作用有关的方解石胶结物

方解石均赋存于粉-细晶白云岩的晶间孔中, 白云石具平直晶面自形晶-半自形晶, 照片均为单偏光, 蓝色铸体片, 茜素红染色, 河坝 1 井, 嘉 II 段. 照片对角线长为 $1.5 \mathrm{~mm}$ (a) 和 $0.75 \mathrm{~mm}$ (b)
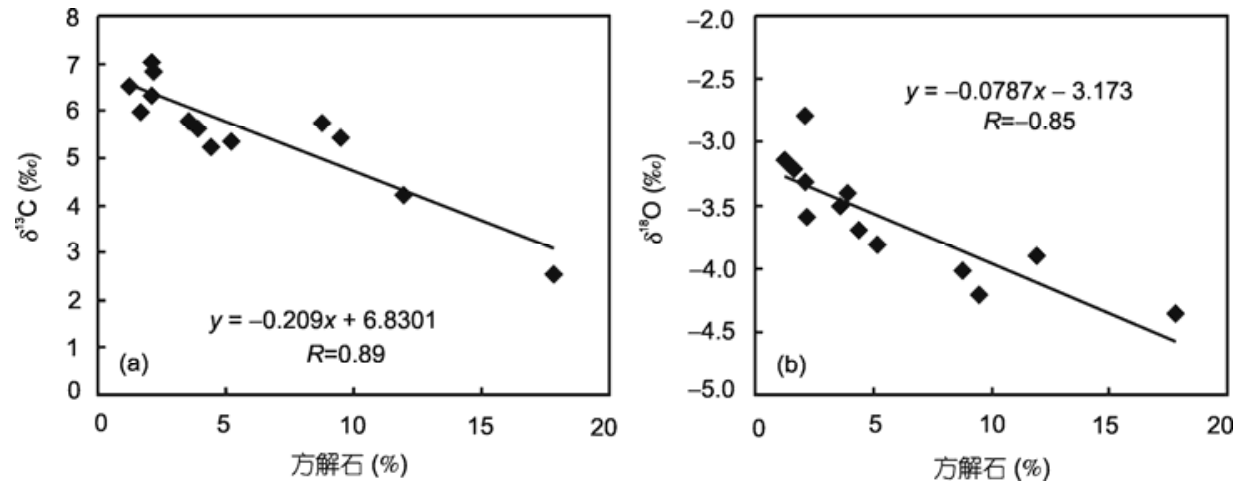

图 9 粉-细晶白云岩中方解石含量与 $\delta^{13} \mathrm{C}$ 和 $\delta^{18} \mathrm{O}$ 值投点图 全部样品都来自河坝 1 井深度间隔 $5.8 \mathrm{~m}$ 的深度范围内

叠世以夹于碳酸盐岩(或蒸发岩)中的火山碎屑岩(俗 称绿豆岩)为界，四川和重庆地区已普遍蚀变成水云 母粘土岩. 由于火山喷发作用的等时性, 该界线已 成为华南早-中三叠世对比的重要直观标志. 本次研 究(图 10(a))的早-中三叠世也以绿豆岩为界. 王彦斌 等 ${ }^{[36]}$ 利用 SHRIMP 对贵州望谟甘河桥剖面早-中三 叠世界线的火山碎屑岩中的锆石进行了 $\mathrm{U}-\mathrm{Pb}$ 年 代学分析, 结果为 $239.0 \pm 2.9 \mathrm{Ma}$ (图 10(a)); 黄思静 等 ${ }^{[37]}$ 曾利用川东渠县三汇石膏矿井下 “绿豆岩”(即 作为火山碎屑岩的水云母粘土岩)上下石膏岩的 ${ }^{87} \mathrm{Sr} /{ }^{86} \mathrm{Sr}$ 比值标定其年龄为 $241.9 \mathrm{Ma}$ ，与王彦斌等 ${ }^{[36]}$ 的测试值接近. 但在图 10(b)中, Payne 等 ${ }^{[13]}$ 所给出 的早/中三叠世界线的年龄值为 $247 \mathrm{Ma}$, 与绿豆岩 的年龄值相差较大, 因而这两个剖面早-中三叠世的 划分可能采用了不同标准, Payne 等 ${ }^{[13]}$ 显然采用了 较新的早-中三叠世界线的年龄值, 虽然这些界线的 年龄值都来源于对火山碎屑物质的放射性同位素年
龄测定，但这些火山物质可能并不是等时的. 如果 是这样, 绿豆岩应在中三叠世地层中, 绿豆岩作为 早-中三叠世界线的古生物地层学的合理性仍需要 继续研究.

\section{2 川东晚二叠世-早三叠世碳同位素曲线与贵州} 同时期曲线的对比

(1) 川东晚二叠世-早三叠世碳同位素曲线(图 10(a))与贵州同时期曲线(图 10(b))具有非常类似的形 态, $\delta^{13} \mathrm{C}$ 值的分布范围也类似, 二叠纪-三叠纪界线附 近的 $\delta^{13} \mathrm{C}$ 极小值之后存在四个峰值超过 $2 \%$ 的 $\delta^{13} \mathrm{C}$ 高值区间(图 10 中的 A D), 后面三个峰可分别与 Dienerian/Smithian, Smithian/Spathian 和 Spathian/ Anisian 界线对应, 但 Spathian/Anisian 的界线落在 了比绿豆岩低的位置.

(2) 图 10 有两个飞仙关组/嘉陵江组界线, 即用 虚线表示的 $F / J$ 界线和 $B$ 峰附近的飞仙关组/嘉陵江 


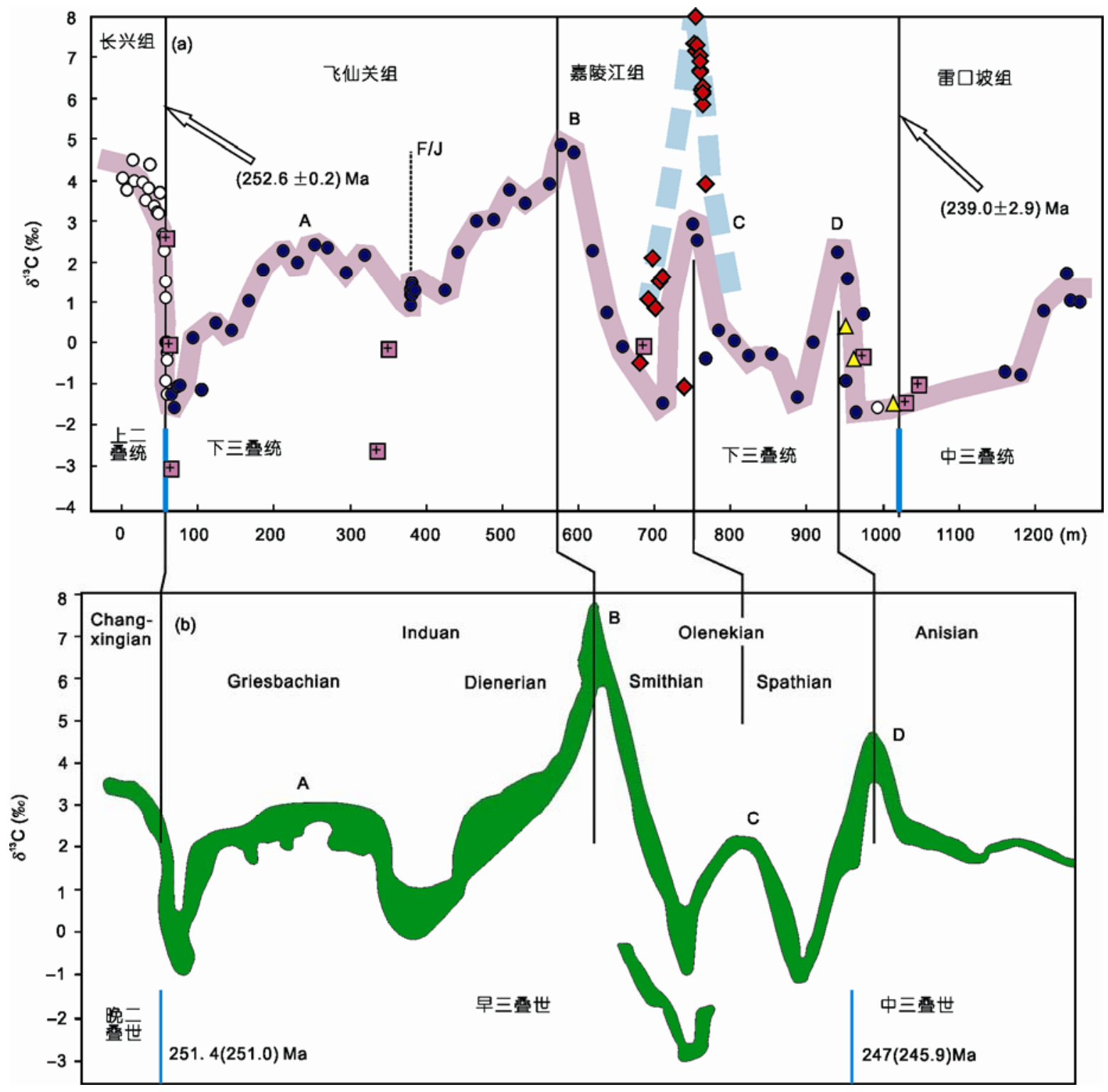

图 10 四川盆地东部晚二叠世-早三叠世碳同位素演化曲线及其与同时代曲线的对比

(a) 四川盆地东部晚二叠世-早三叠世碳同位素演化曲线, 长兴组/飞仙关组界线和嘉陵江组/雷口坡组界线的年龄值分别据文献[30,36], 方 框代表 $\mathrm{Mn} / \mathrm{Sr}$ 比值大于 2 的样品, 空心圆圈代表中梁山剖面样品, 实心圆圈代表仰天窝剖面的样品, 菱形代表河坝 1 井的样品, A D 和 F/J 的意义见正文中讨论; (b) 综合的贵州晚二叠世-早三叠世碳同位素曲线, 据文献[13], 图中年龄值据文献[38 41], 其中括号中的年龄值据 文献[41]

组界线. 前者是我们在野外识别的岩性界线，该界线 以后没有再出现作为飞仙关组代表性岩石的紫红色 泥质微晶灰岩或钙质泥岩; 后者与 $1 / 50000$ 地质图 ${ }^{1) 飞 ~}$ 仙关组顶界对应, 前边已经讨论. 前一个界线 $(\mathrm{F} / \mathrm{J}$ 界 线)可能相当于 Griesbachian/Dienerian 的界线, 后 一个中与 Dienerian/Smithian 的界线对应，但目前仍 缺乏生物地层学资料的支持.

\section{3 早三叠世碳同位素曲线的解释与讨论}

川东早三叠世碳同位素曲线最为重要的特征是 其代表了海水 $\delta^{13} \mathrm{C}$ 值在很短时间内(分别按 245.9 和 $251 \mathrm{Ma}$ 作为二叠纪-三叠纪和早-中三叠世界线的年 龄值 ${ }^{[41]}$, 该时间跨度只有约 $5 \mathrm{Ma}$ ) 的巨大波动, 从约 $-2 \%$ 的最小值变化到 $8 \%$ 附近的最大值, 变化幅度高 达 $10 \%$, 这种变化幅度只限于早三叠世, 因为这种 
大幅度波动在早-中三叠世界线附近突然停止. 从图 11 可以看出, 与早三叠世相邻的二叠纪大部分时间 和中三叠世海水的碳同位素的变化都十分稳定, $\delta^{13} \mathrm{C}$ 值的变化幅度不会超过 $2 \%$. 前人的主要解释是生物 大绝灭后的延迟复苏过程中环境的不稳定性对碳循 环的影响 ${ }^{[13]}$. 更为具体机制涉及到太多的与全球碳 循环有关的深层次问题, 加之早三叠世全球海水碳 同位素组成数据的积累仍然非常有限, 例如早三叠 世海相碳酸盐的碳同位素组成是否确实具有地方性 的的问题, 仍需要更多碳同位素数据的积累来证实. 因而, 到现在为止, 人们对早三叠世海相碳酸盐碳同 位素组成及变化的解释仍然有待深入. 我们从现有 资料出发, 认为早三叠世海水很高的 $\delta^{13} \mathrm{C}$ 值和碳同 位素组成的巨大波动可能与如下几个原因有关.

(1) 早三叠世海相碳酸盐具有很高的 $\delta^{13} \mathrm{C}$ 值(显 生宙最大值), 显示同期有机碳的巨大埋藏量, 但早 三叠世陆地缺乏煤的沉积, 因而通过陆生植物创造 原始有机碳的数量有限, 说明菌、藻类是早三叠世有 机碳的主要原始创造者, 菌、藻类在现代海洋碳循环 中的重要地位已得到了充分的肯定 ${ }^{[43]}$, 它们是大绝 灭事件后首先复苏的生物, 其光合作用重建了被大 灭绝摧毁的有机碳的同位素分馏效应.

(2) 早三叠世所存在菌、藻类的过度繁盛与生物 绝灭后相关的海洋食物链没有得到恢复有关, 二叠 纪-三叠纪界线生物绝灭事件后全球有 $90 \%$ 左右的海
洋物种消失 ${ }^{[1,2]}$, 早三叠世海洋无脊椎动物不仅数量 少, 体型也很小, 这使得在灾变中存活下来的菌、藻 类无法被充分摄取从而泛滥, 这可以通过早三叠世 与蓝绿藻成因有关的沉积构造 (如大量的层纹石, 包 括一部分所谓的条带状层理)的发育程度仅次于前寒 武纪的地质现象来证明, 与之有关的沉积构造也是 一种所谓的错时相, 形成机制类似于如扁平砾石砾 岩、蠕虫状灰岩(其形成机制在很大程度上与藻类繁 盛有关 ${ }^{[44]}$ )和微生物岩等其他错时相 ${ }^{[45]}$, 早三叠世碳 同位素的强烈波动及多个 $\delta^{13} \mathrm{C}$ 高值可能预示了菌类 和藻类在大灭绝后出现的阵发性的繁盛.

(3) 上扬子地区三叠系嘉陵江组具很高 $\delta^{13} \mathrm{C}$ 值 (可达 $8 \%$ ) 的白云岩(尤其是嘉 II 段的白云岩)可能是 甲烷形成过程中的副产物, 说明海洋中甲烷的形成 有利于白云石的沉淀.

(4) 近年来, 不少学者将二叠-三叠之交碳同位 素大规模的负漂移归因于甲烷水合物的释放带来的 大量轻碳 ${ }^{[46 ~ 48]}$. 如果这种关联是客观存在的, 那么, 按照 Dickens ${ }^{[48]}$ 将甲烷水合物看作是外生碳循环系统 的电容器的思路, 大灭绝之后甲烷水合物的状态很 可能迅速地由释放转变为吸收, 而产甲烷菌的活跃 (原因也与海洋食物链没有得到恢复有关)很可能为 这一转变提供了契机, 甲烷的形成可以在局部地区 大幅度提高海相碳酸盐的碳同位素组成, 这可能是 上扬子地区海相碳酸盐的 $\delta^{13} \mathrm{C}$ 最大值高达 $8 \%$ 的关

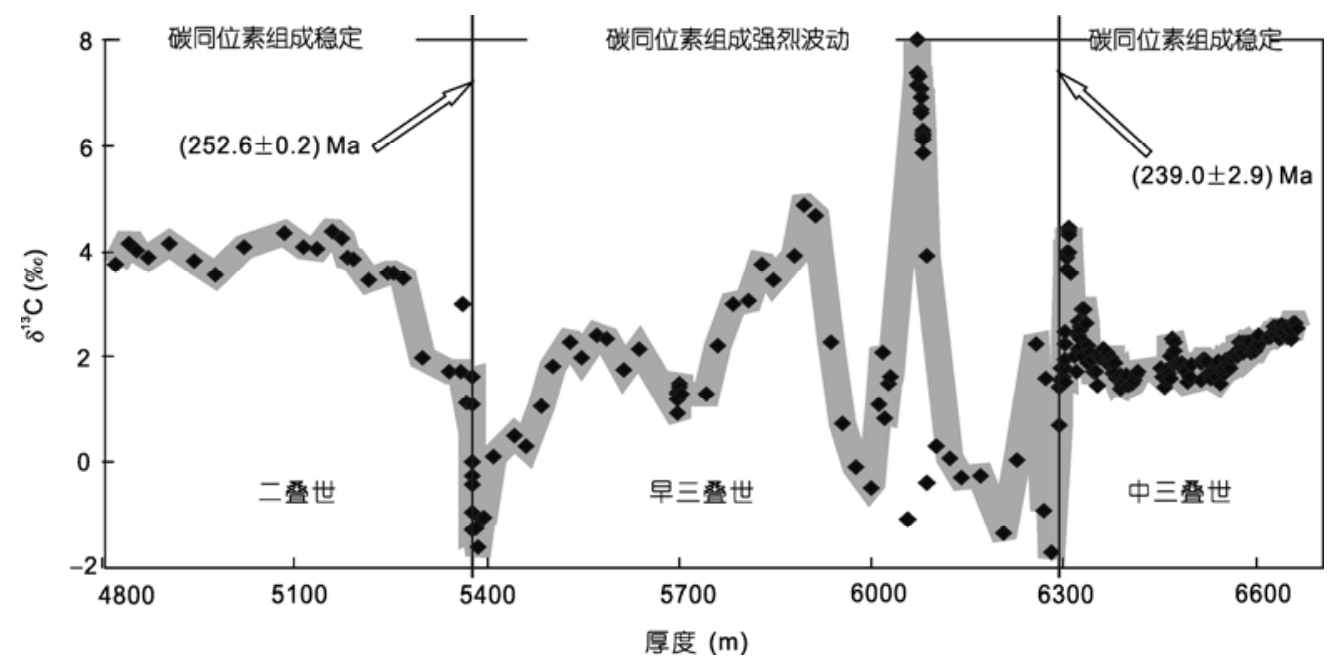

图 11 二叠纪-中三叠世海相碳酸盐的碳同位素演化曲线

二叠纪部分据文献[42], 中三叠世部分据文献[13], 早三叠世部分来自本文(包括河坝 1 井数据). 地层厚度从泥盆纪起算[42], 不同剖面从界 线处累积 
键, 并可能导致海相碳酸盐碳同位素组成的地方性 色彩. 同时, 上扬子地区海相碳酸盐的 $\delta^{13} \mathrm{C}$ 值显著高 于下扬子地区，表明上扬子地区比下扬子地区具有 更大的有机碳埋藏量和生烃能力, 早三叠世形成的 甲烷水合物可能为上扬子地区的天然气提供烃源, 但下扬子地区不具有这样的优势.

(5) 海相碳酸盐沉积直接依赖于生物, 尤其是无 脊椎动物, 二叠纪-三叠纪界线生物绝灭事件造成制 造海相碳酸盐的无脊椎动物大量消失 (早三叠世碳 酸盐颗粒以非生物成因为主, 如大量的鲕粒岩), 加 之陆地上植被缺乏, 使得地球上很多地方早三叠世 都以巨厚的碎屑沉积为主 ${ }^{[4]}$. 海相碳酸盐沉积的减少 使得无机碳库的储备 (这是碳循环系统的主要电容 器)严重不足, 这可能造成海相碳酸盐自身同位素组 成的大幅度波动的另一原因. 但碳酸盐碳库的碳在 数量上如何影响大气 $\mathrm{CO}_{2}$ 和溶于海水中的 $\mathrm{CO}_{2}$ 的碳 同位素组成及整个碳循环方式仍然需要更为定量的 研究.

（6）基于前边的讨论, 我们可以认为, 海洋无脊 椎动物的数量和海相碳酸盐的数量在全球碳循环中 具有和大陆植被同等重要的作用. 大陆植被和海相 碳酸盐(尤其是钙质无脊椎动物, 如多细胞生物礁、钙 质藻、䥻质海绵和珊瑚等) 是两个最为重要的海水碳 同位素组成的调节器, 它们在数量上的不足会造成 海水碳同位素组成的大幅度波动, 说明一个健康的 生态系统中不仅应该有足够的绿色植被, 还应有数 量较多且门类多样化的海洋动物群, 因而我们应该 像保护热带雨林那样保护海洋钻质无脊椎动物, 尤 其是以各种方式存在的生物礁.

\section{4 结论}

(1) 四川盆地东部晚二叠-早三叠世海相碳酸盐 具有较高的锶含量、较低的锰含量和很低的锰/锶比 值, 显示其对古海水信息具有良好的代表性, 建立的 晚二叠世-早三叠世碳酸盐的碳同位素演化曲线与前 人在贵州建立的同期碳酸盐碳同位素演化曲线具有
很好的可对比性.

(2) 建立的晚二叠世-早三叠世碳酸盐的碳同位 素演化曲线与前人在下扬子地区 (如安徽巢湖地区) 建立的同时代演化曲线存在显著的差别, 包括 $\delta^{13} \mathrm{C}$ 的数值和曲线的演化趋势.

(3) 上扬子地区三叠系嘉陵江组具很高 $\delta^{13} \mathrm{C}$ 值 (可达 $8 \%$ ) 的白云岩(尤其是嘉 II 段的白云岩)可能是 甲烷形成过程中的副产物, 说明海洋中甲烷的形成 有利于白云石的沉淀.

(4) 四川盆地东部早三叠世海相碳酸盐的碳同 位素组成具显生宙最大的波动范围, 在约 $5 \mathrm{Ma}$ 的时 间 $\delta^{13} \mathrm{C}$ 值从约 $-2 \%$ 的最小值变化到 $8 \%$ o 的最大值, 变 化幅度达到 $10 \%$, 但其全球性仍然需要进一步证实, 因为下扬子地区(如安徽巢湖地区)海相碳酸盐不存 在这样的大幅度波动, 或具有不同的波动方式(如 $\delta^{13} \mathrm{C}$ 值从约- $6 \%$ 的最小值变化到 $4 \%$ ) .

(5) 上扬子地区海相碳酸盐的 $\delta^{13} \mathrm{C}$ 值显著高于 下扬子地区，表明上扬子地区比下扬子地区具有更 大的有机碳埋藏量和生烃能力, 早三叠世形成的甲 烷水合物可能为上扬子地区的天然气提供烃源, 但 下扬子地区可能不具有这样的优势.

（6）早三叠世全球范围大陆植被的减少、海洋钲 质无脊椎动物和海相碳酸盐数量的减少, 以及海洋 系统中菌、藻类的过度繁盛, 产甲烷菌的活跃以及甲 烷的形成可能是早三叠世海水极高的 $\delta^{13} \mathrm{C}$ 的值和 同位素组成大幅度波动的重要原因. 甲烷的形成在 局部地方大幅度提高了海水的 $\delta^{13} \mathrm{C}$ 的值, 这可能是 海相碳酸盐碳同位素组成具有一定地方性色彩的原 因. 这种现象在早-中三叠世界线附近结束, 海水 $\delta^{13} \mathrm{C}$ 值得以稳定, 表明地球系统生态环境得以重建 和恢复.

(7) 早三叠世海水碳同位素演化曲线告诉我们, 作为碳同位素调节器的大陆植被和海洋钙质无脊椎 动物在地球生态系统中具有不可替代的作用. 我们 不但要保护热带雨林, 也要像保护热带雨林那样保 护海洋钙质无脊椎动物, 尤其是以各种方式存在的 生物礁.

致谢石和、李志明、范明、徐二社、张文涛、胡作维、刘吴年、黄培培、王庆东、张雪花、佟宏鹏、刘丽红、孙伟、 刘涛、魏文文等人参加了野外或实验室工作, 在此表示衰心感谢. 同时感谢审稿人对本文提出的建设意见. 


\section{参考文献}

1 Raup D M. Size of the Permo-Triassic bottleneck and its evolutionary implications. Science, 1979, 206: 217-218

2 Erwin D H. The Great Paleozoic Crisis: Life and Death in the Permian: Critical Moments in Paleobiology and Earth History Series. New York: Columbia University Press, 1993. 1-338

3 Veizer J, Ala D, Azmy K, et al. ${ }^{87} \mathrm{Sr} /{ }^{86} \mathrm{Sr}, \delta^{13} \mathrm{C}$ and $\delta^{18} \mathrm{O}$ evolution of phanerozoic seawater. Chem Geol, 1999, 161: 59-88

4 Korte C, Kozur H W, Bruckschen P, et al. Strontium isotope evolution of Late Permian and Triassic seawater. Geochim Cosmochim Acta, 2003, 67: 47-62

5 Tong J N, Qiu H O, Zhao L S, et al. Lower Triassic inorganic carbon isotope excursion in Chaohu, Anhui Province, China. China Univ Geosci, 2002, 13: 98-106

6 Zuo J X, Tong J N, Qiu H O, et al. Carbon isotope composition of the Lower Triassic marine carbonates, Lower Yangtze region, South China. Sci China Ser D-Earth Sci, 2006, 49: 225-241

7 Korte C, Kozur H W, Veizer J. $\delta^{13} \mathrm{C}$ and $\delta^{18} \mathrm{O}$ values of Triassic brachiopods and carbonate rocks as proxies for coeval seawater and palaeotemperature. Palaeogeogr Palaeoclimatol Palaeoecol, 2005, 226: 287-306

8 Korte C, Kozur H W, Joachimski M M, et al. Carbon, sulfur, oxygen and strontium isotope records, organic geochemistry and biostratigraphy across the Permian/Triassic boundary in Abadeh, Iran. Int J Earth Sci, 2004, 93: 565-581

9 Korte C, Kozur H W. Carbon isotope stratigraphy across the Permian/Triassic boundary at Jolfa (NW-Iran), Peitlerkofel (Sas de Pü tia, Sass de Putia), Pufels (Bula, Bulla), Tesero (all three Southern Alps, Italy) and Gerennavár (Bükk Mts., Hungary). J Alp Geol, 2005, 47: 119-135

10 Kozur H W. Integrated ammonoid, conodont and radiolarian zonation of the Triassic. Hallesches Jahrb Geowiss, 2003, 25: 49-79

11 Kozur H W. Integrated ammonoid, conodont and radiolarian zonation of the Triassic and some remarks to stage/substage subdivision and the numeric age of the Triassic stages. Albertiana, 2003, 28: 57-74

12 Horacek M, Brandner R, Abart R. Carbon isotope record of the P/T boundary and the Lower Triassic in the southern Alps: Evidence for rapid changes in storage of organic carbon. Palaeogeogr Palaeoclimatol Palaeoecol, 2007, 252: 347-354

13 Payne J L, Lehrmann D J, Wei J, et al. Large perturbations of the carbon cycle during recovery from the end-Permian extinction. Science, 2004, 305: 506-509

14 黄思静. 重庆中梁山和广元上寺 P-T 界线粘土层中粘土矿物的类型及成因. 成都地质学院学报, 1992, 19: 66-73

15 黄思静. 四川重庆中梁山 P/T 界线粘土层中非粘土组分的研究. 沉积学报, 1993, 11: 105-113

16 黄思静. 海相碳酸盐矿物的阴极发光性与其成岩蚀变的关系. 岩相古地理, 1990, 10: 9-15

17 胡作维, 黄思静, Qing H R, 等. 四川东部华菳山海相三叠系锶同位素组成演化及其与全球对比. 中国科学 D辑: 地球科学, 2008, 38: $157-166$

18 黄思静, Qing H R, 黄培培, 等. 晚二叠世-早三叠世海水的锶同位素组成与演化一基于重庆中梁山海相碳酸盐的研究结果. 中国科 学 D 辑: 地球科学, 2008, 38: 273-383

19 Brand U, Veizer J. Chemical diagenesis of multicomponent carbonate system-2: Trace elements. J Sediment Petrol, 1980, 50: 1219-1236

20 黄思静, Qing H R, 胡作维, 等. 川东三叠系飞仙关组碳酸盐岩的阴极发光特征与成岩作用. 地球科学一一中国地质大学学报, 2008 , 33: 26-34

21 Walter M R, Veevers J J, Calver C R, et al. Dating the 840-544 Ma Neoproterozoic interval by isotopes of strontium, carbon, and sulfur in seawater, and some interpretative models. Precambrian Res, 2000, 100: 371-433

22 黄思静, 王春梅, 黄培培, 等. 碳酸盐成岩作用的研究前沿和值得思考的问题. 成都理工大学学报(自然科学版), 2008, 35: 1-0

23 Derry L A, Keto L, Jacobsen S, et al. Sr isotopic variations in Upper Proterozoic carbonates from Svalbard and east Greenland. Geochim Cosmo Acta, 1989, 53: 2331-2339

24 Kaufman A J, Jacobsen S B, Knoll A H. The Vendian record of Sr- and C-isotopic variations in seawater: Implications for tectonics and paleoclimate. Earth Planet Sci Lett, 1993, 120: 409-430

25 Kaufman A J, Knoll A H, Awramik S M. Biostratigraphic and chemostratigraphic correlation of Neoproterozoic sedimentary successions: Upper Tindir Group, northwestern Canada, as a test case. Geology, 1992, 20: 181-185

26 黄思静. 碳酸盐岩的成岩作用. 北京: 地质出版社, 2010. 103-114

27 Magaritz M, Anderson R Y, William T, et al. Isotope shifts in the Late Permian of the Delaware Basin, Texas, precisely timed by varved sediments. Earth Planet Sci Lett, 1983, 66: 111-124

28 黄思静, 黄喻, 兰叶芳, 等. 四川盆地东北部晚二叠世-早三叠世白云岩与同期海水锶同位素组成的对比研究. 岩石学报, 2011 , 27 : 3831-3842 
29 Huang S J, Huang K K, Fan M, et al. TSR-Derived Authigenic Calcites in Triassic Dolomite, NE Sichuan Basin, China- — A case study of Well HB-1 and Well L-2. J Earth Sci, 2012, 23: 88-96

30 Mundil R, Ludwig K R, Metcalfe L, et al. Age and Timing of the Permian mass extinctions: U/Pb dating of closed-system zircons. Science, 2004, 305: 1760-1763

31 Claoue-Long J C, Zhang Z C, Ma G G, et al. The age of the Permain-Triassic boundary. Earth Planet Sci Lett, 1991, 105: 182-190

32 陈锦石, 邵茂茸, 霍卫国, 等. 浙江长兴二叠系和三叠系界限地层的碳同位素. 地质科学, 1984, 19: 88-93

33 Magarita M, Bar R, Baud A, et al. The carbon isotope shift at the Permian-Triassic boundary in the Southern Alps is gradual. Nature, 1988, 331: 337-389

34 Holser W T, Magaritz M. Events near the Permian-Triassic boundary. Modern Geol, 1987, 11: 155-180

35 黄思静. 上扬子二叠系-三叠系初海相碳酸盐岩的碳同位素组成与生物绝灭事件. 地球化学, 1994, 23: 60-67

36 王彦斌, 刘敦一, 姚建新, 等. 黔西南下-中三叠统界线年龄. 地质学报, 2004, 78: 587-590

37 黄思静, 裴昌蓉, 卿海若, 等. 四川盆地东部海相下、中三叠统界线的锶同位素年龄标定. 地质学报, 2006, 80: 1691-1698

38 Bowring S A, Erwin D H, Jin Y G, et al. U/Pb zircon geochronology and tempo of the end-Permian mass extinction. Science, 1998, 280: $1039-1045$

39 Martin M W, Lehrmann D J, Bowring S A, et al. Timing of Lower Triassic carbonate bank buildup and biotic recovery following the end-Permian extinction across the Nanpanjiang Basin, South China. In: 2001 Annual Meeting, Geol Soci Amer, 2001, 33: 201

40 Mundil R, Brack P, Meier M, et al. High resolution U-Pb dating of Middle Triassic volcaniclastics: Time-scale calibration and verification of tuning parameters for carbonate sedimentation. Earth Planet Sci Lett, 1996, 141: 137-151

41 章森桂, 张允白, 严惠君. “国际地层表”(2008)简介. 地层学杂志, 2009, 33: 1-10

42 黄思静. 上扬子地台区晚古生代海相碳酸盐岩的碳、锶同位素研究. 地质学报, 1997, 71: 45-53

43 Kolber Z S, Plumley F G, Lang A S, et al. Contribution of aerobic photoheterotrophic bacteria to the carbon cycle in the ocean. Science, 2001, 292: 2492-2495

44 黄思静. 蠕虫状灰岩及其成因. 成都地质学院学报, 1984, 11: 60-67

45 赵小明, 童金南, 姚华舟, 等. 华南早三叠世错时相沉积及其对复苏期生态系的启示. 中国科学 D 辑: 地球科学, 2008, 38: 15641574

46 Retallack G L. Postapocalyptic greenhouse paleoclimate revealed by earliest Triassic paleosols in the Sydney Basin, Australia. Geol Soc Am Bull, 1999, 111: 52-70

47 Krull E S, Retallack G J. $\delta^{13} \mathrm{C}$ depth profiles from paleosols across the Permian-Triassic boundary: Evidence for methane release. Geol Soc Am Bull, 2000, 112: 1459-1472

48 Dickens G R. Rethinking the global carbon cycle with a large, dynamic and microbially mediated gas hydrate capacitor. Earth Planet Sci Lett, 2003, 213: 169-183 